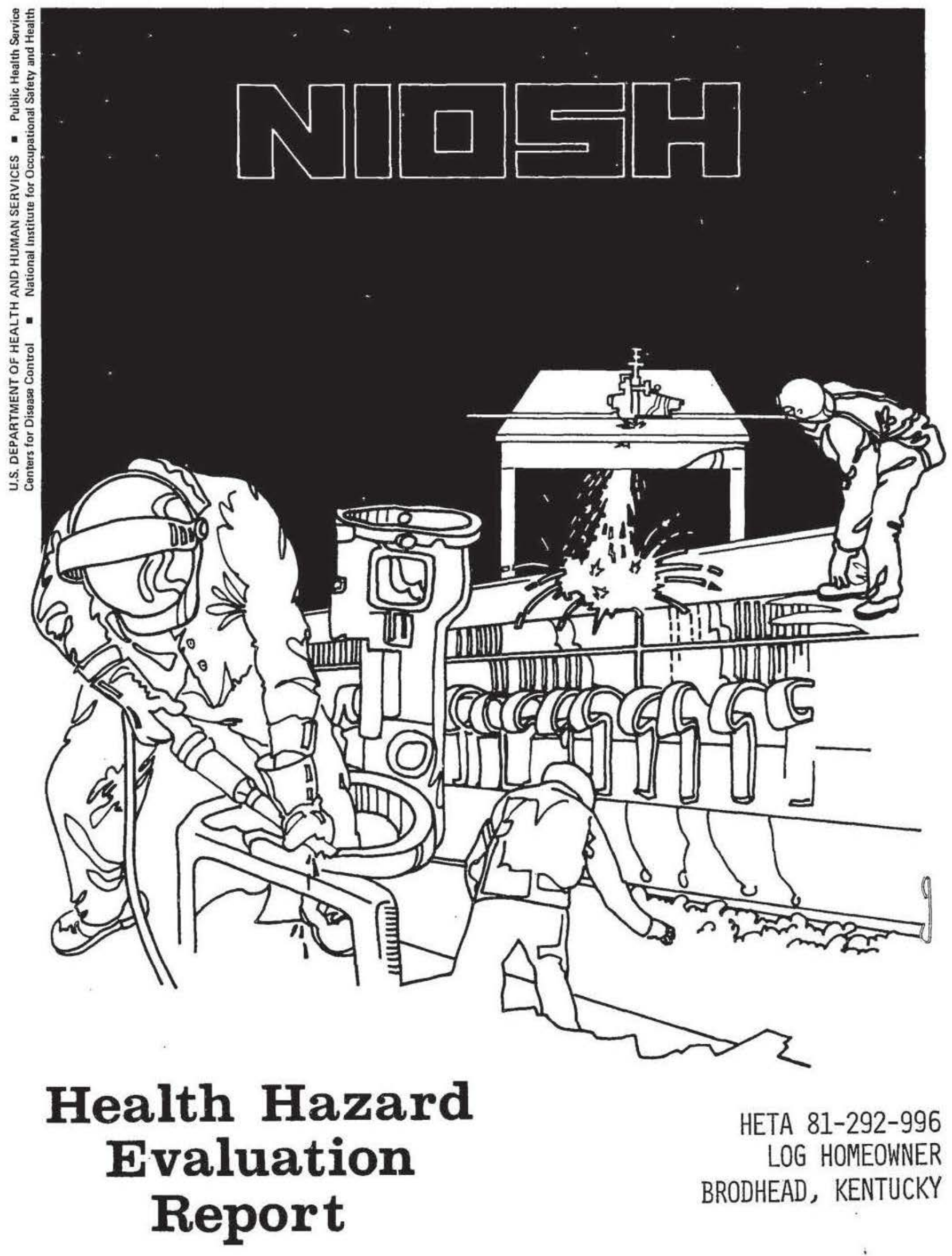


The Hazard Evaluations and Technical Assistance Branch NIOSH conducts field investigations of possible health hazards in the workplace. These investigations are conducted under the authority of Section 20(a)(6) of the Occupational Safety and Health Act of 1970, 29 U.S.C. 669(a)(6) which authorizes the Secretary of Health and Human Services, following a written request from any employer or authorized representative of employees, to determine whether any substance normally found in the place of employment has potentially toxic effects in such concentrations as used or found.

The Hazard Evaluations and Technical Assistance Branch also provides, upon request, medical, nursing, and industrial hygiene technical and consultative assistance (TA) to Federal, state, and local agencies; labor; industry and other groups or individuals to control occupational health hazards and to prevent related trauma and disease.

Mention of company names or products does not constitute endorsement by the National Institute for Occupational Safety and Health. 
HETA 81-292-996

NOVEMBER 1981

LOG HOMEOWNER

BRODHEAD, KENTUCKY
NIOSH INVESTIGATOR :

PATRICIA LYNNE MOODY, M.D.

I. SUMMARY

In April 1981, the National Institute for Occupational Safety and Health investigated a report of a possible toluene overexposure in an occupant of a log home in Brodhead, Kentucky. Subsequent to the caulking of the log walls of his home with a "butyl" caulk in February 1981, the affected individual remained in the home and developed headache and disorientation over a three day period, followed by a profound nosebleed requiring blood transfusions, and abnormal elevations of his liver enzymes. All three other family members also reportedly developed less severe nosebleeds, and one experienced headache. Although no timely environmental measurements were made, air sampling conducted by a private environmental consulting firm six weeks after the caulking yielded air levels of toluene of $2 \mathrm{ppm}$ in the home. Laboratory analysis of the caulk showed it to be approximately $6 \%$ toluene, $0.5 \%$ xylene, and $15.5 \%$ "naphtha" on a weight for weight basis. The history of the most affected individual's illness, and the additional symptoms in other family members, suggests an association with exposure to volatile solvents contained in the caulk.

This study suggests that residents of a log home in Brodhead, Kentucky may have been exposed to high airborne concentrations of toluene, xylene, and naphtha after the walls of their home were caulked with a "buty.]" caulk. Typical symptoms of solvent overexposure--headache, nausea, fatigue, and disorientation--occurred in one occupant, headache occurred in a second individual, and 211 four persons experienced nosebleeds, one of them severe. Ine individual who experienced both the profound nosebleed and marked central nervous system effects also exhibited transient abnormalities of liver function following the incident. Recommendations are made for the proper labelling and proper work and ventilation practices to be used with materials containing volatile solvents.

Keywords: SIC code 9999, "butyl" caulk, epistaxis, solvents (toluene, xylene, naphtha), solvent intoxication, hepatotoxicity, log home 
Page 2. HE/TA 81-292

II. INTRODUCTION AND BACKGROUND

On April 13, 1981, a NIOSH medical officer received a call from a resident of Brodhead, Kentucky who reported that he had become $i 11$ after his log home was caulked with a "butyl" caulk in February 1981. On the first day of caulking, the 45 year-old white male resident, his wife, and their two teenage sons noted a strong odor and experienced headaches and mild dizziness. The man and woman spent most of their time indoors. The man slept downstairs in a bedroom with bare log walls, while his wife and sons slept upstairs in a portion of the house that had not been caulked. Over the next three days, the man felt progressively more $i 11$, experiencing nausea, increasingly severe headache, and mild feelings of disorientation. On the fourth day, February 27, he developed a severe nosebleed. His wife and sons also reportedly developed nosebleeds which were less severe. That evening, the man was admitted to a local hospital in Berea, Kentucky for uncontrolled bleeding from the nose. On February 28, he was transferred by ambulance to a hospital in Lexington, Kentucky for recurrent, uncontrolled epistaxis (nosebleed). On admission to the hospital in Lexington, the patient had normal blood clotting parameters (prothrombin time, partial thromboplastin time, and platelets). Rebleeding continued intermittently, and over the next five days he received eight units of blood, one of which was noted to be slightly hemolyzed. During this period, he received small doses of several drugs, including diazepam and oxycodone hydrochloride, and regular doses of a broad-spectrum

penicillin. He finally went to surgery on March 4, 1981 for examination and cautery of multiple superficial bleeding sites in the left posterior nasal passage. On March 6 , a routine battery of blood tests showed that his liver function parameters were abnormal: his total bilirubin was $3.3 \mathrm{mg} / \mathrm{dl}$ (nomal 0.2 to 1.2 ), alkaline phosphatase $127 \mathrm{U} / 1$ (normal 30-115), GGT (gamma glutaryl transferase) $187 \mathrm{U} / 1$ (normal up to 65), SGOT (alanine amino transferase) 120 (normal up to 41), and LDH (lactic dehydrogenase) 344 (normal 100-225). On March 9, his alkaline phosphatase was up to 231 , but his SGOT had fallen to 52, his LDH to 256, and his bilirubin and protein were normal.

He went home on March 10 but was readmitted to the hospital on March 13 for recurrent bleeding from the nose. Again his coagulation parameters--including bleeding time and fibrin split products--were normal. The bleeding abated spontaneously. By March 15, all of his liver function studies had returned to normal with the exception of the alkaline phosphatase, which remained slightly elevated at 149 . The alkaline phosphatase remained mildly elevated in late April.

The affected individual was asymptomatic prior to the caulking, and he had no prior history of nosebleeds. His only medication at the time of admission to the hospital in Berea was a combination tablet of spironolactone and hydrochlorthiazide for high blood pressure. His blood pressure on admission to Berea was 180/105 and was $160 / 100$ on admission to the hospital in Lexington. Other past medical history included leg cramping with walking and evidence of severe atherosclerotic disease of the iliac and femoral arteries (diagnosed by femoral angiogram in 1978), and the passage of a kidney stone in 1979. 
Page 3. HE/TA 81-292

He has no past history of hepatitis or gall bladder disease. The patient works seasonally as a construction work superintendent. He drinks no alcoholic beverages and has smoked one pack of cigarettes daily for 20 years.

\section{NIOSH INVESTIGATION}

\section{A. Site visit}

On April 20, NIOSH medical officers visited the log home and interviewed the occupants. The family had moved into the completed log home in January 1980. During the following year, the logs began to shrink and spaces appeared between them. Rising heating bills prompted the owner of the house to report this to the manuf acturer. The company agreed to have the house caulked and did so in February 1981. The caulking was performed from the outside of the house. A large powered gun drew caulk from a five-galion can and forcefully extruded it into the spaces between the logs. Immediately after filling a crack with caulk, the applicator partially sealed the fresh compound in by nailing a strip of wooden molding over it, thereby covering the caulk which would otherwise have been exposed to the open outside air. Because of cold outside temperatures, the occupants of the house did not open windows to ventilate the house, nor were they instructed to do so. According to the occupants, $51 / 2$ five-gallon cans of caulk were used to caulk the first floor of the house.

The family requested the services of a private environmental consulting firm after the affected individual returned home from the hospital. On April 5, six weeks after the caulking, a representative of a Cincinnati-based firm performed an environmental evaluation at the log home. Air sampling reportedly yielded air levels of 2 ppm (parts per million) of toluene in the man's bedroom. Gas chromatographic-mass spectrophotometric (GC-MS) examination of a sample of the caulk done by the same consulting firm showed peaks of toluene and nonene, with smaller amounts of tetrahydrofuran, 1,1,1-trichloroethane, C7-C9 isomers, decane, and $\mathrm{Cl} 10$ hydrocarbon isomers. There were also very small peaks for benzene and hexane.

Only the downstairs portion of the house was constructed of logs and had required caulking, and only the bedroom in which the affected individual slept had bare log walls inside (other inside walls were covered with panelling). In this bedroom, NIOSH investigators observed that the caulk had extruded on the inside between the logs in strips that averaged 1/4 inch in width. The calculated surface area of exposed caulk was 4.4 square feet in a room which measured 11 feet by 12 feet by 7.75 feet or 37.9 cubic yards. A large wood stove in the living room adjacent to the downstairs bedroom, and a central electric forced hot air system provided heat for the house. A pan of water on the wood stove provided some humidification; the electric heat system had no humidifier. Although the house thermostat had no thermometer on it (indicating instead a "comfort" range), NIOSH investigators noted that 
the air in the house seemed uncomfortably warm and dry. The occupants of the house reported that the temperature and humidity in the house on the day of our visit were approximately the same as in February and March.

NIOSH investigators obtained a sample of the caulk from below the surface of the caulk that remained in a covered, half-filled 5-gallon can and requested from our laboratory a quantitative analys is for toluene, xylene, and benzene, and a qualitative analysis for other contents. We aiso requested that air measurements be taken in a chamber constructed so that the volume of the chamber and the surface area of caulk exposed in it would correspond to the volume of the bedroom and the measured surface area of exposed caulk, but laboratory. personnel deemed this experimentally unfeasible.

B. Results of the Laboratory Investigation

A sample of caulk extracted with carbon disulfide and analyzed by GC/MS showed that the caulk contained a large amount of toluene and a series of peaks consistent with the $\mathrm{C} 9-\mathrm{C} 12$ alkanes plus some xylene and higher aromatics. This type of pattern is typical of mineral spirits or Stoddard solvent naphtha ("petroleum distillates"). A quantitative analysis on $974 \mathrm{mg}$ of caulk showed that any benzene present would have been below the lowest benzene analytic standard of $0.02 \%$. Two smaller samples were assayed for toluene, xylene, and naphtha (two samples were used in an effort to achieve greater accuracy). The table below shows the values obtained on those analyses.

Samp le 1

(27 mg caulk)

Toluene $(\mathrm{mg})$ $\%$ toluene (weight/weight)

Xylene $(\mathrm{mg})$ $\%$ xylene $(w / w)$

"Naphtha" \%"naphtha" (w/w)
1.6

5.9

0.15

0.55

4.1

15.2
Sample 2

(12 mg caulk)

C. Contact with the Log Home Council

The Log Home Council in Falls Church, Virginia is a trade organization of $\mathrm{log}$ home manufacturers, its 21 member companies comprising about $10 \%$ of the approximately 200 log home manufacturers in the United States and Canada. The manufacturer of the $\log$ home involved in this case is not a member of the trade organization. NIOSH contacted the Log Home Council about its recommendations for the timing, procedure, and type of caulk used in log homes. Because of wide variation in both architectural and structural features, the Council has no official policies regarding caulking. Accordingly, NIOSH contacted the 13 member companies located in the eastern U.S. to obtain a sample of recommended practices. 
Page 5. HE/TA 81-292

of the 13 companies contacted, 7 recommend some type of caulking. The other 6 rely on either tightly fitted tongue-in-groove construction alone, or on strips of foam, Neoprene, vinyl, or fibrous glass insulation placed between the logs at the time of construction. of the 7 who recommend caulk, all suggest that caulking should be done at the time the house is constructed. Two of this group recommend the same type of caulk that was used in the present case. One of these manufacturers indicated that he also recommends recaulking as needed, and that he would not have hesitated to use the "butyl" caulk on interior as well as exterior surfaces. All seven of those recommending caulking stated, however, that recaulking the interior walls would be unusual, and that extrusion of externally-applied caulk onto the inner surfaces of the house at the time of recaulking would be distinctly unusual, since the spaces between previously-caulked logs would be narrow. The other caulks recommended by the manufacturers include urethane and other "rubber" caulks which, like the caulk in this case, are soluble in petroleum-based solvents. None of the manuf acturers reported having heard of any health problems related to the use of caulk in log homes.

IV. EVALUATION CRITERIA

The NIOSH-recommended standards for exposure to all substances are promulgated on a maximum 10 hour workday, 40 hour work week exposure at levels which may be considered safe over a working lifetime. In the workplace setting, NIOSH recommends that an eight-hour time weighted average (TWA) for airborne toluene and xylene exposure be 1 imited to 100 ppm, with a ceiling limit of $200 \mathrm{ppm}$ for a ten minute sampling period. The Occupational Safety and Health Administration requires that toluene exposure be 1 imited to a TWA of $200 \mathrm{ppm}$ (with a $500 \mathrm{ppm}$ ceiling), and that xylene exposure be limited to a TWA of $100 \mathrm{ppm}$. The OSHA standard for petroleum naphtha is $500 \mathrm{ppm}$.

By contrast with the workplace, the situation under investigation here is one in which the person primarily involved was exposed to unknown but possibly high concentrations of toluene and naphtha, and lesser amounts of xylene, almost continuously for three days. No exposure standards exist for continuous exposure. Although toluene is metabolized predominantly to hippurate and is excreted in the urine, and continuous exposure would presumably lead to a metabolic equilibrium, some of the effects may be assumed to be cumulative, so that continuous exposure may result in more profound, if transient, toxicity.

Both toluene and xylene are methylated aromatic ring structures with similar properties. Widely used as solvents, both may be absorbed through inhalation or skin contact. Both may cause irritation of the eyes, mucous membranes, and skin; central nervous system intoxication; and transient liver and/or kidney dysfunction. At high exposure levels, xylene may also cause pulmonary edema (fluid accumulation in the air spaces of the lungs) and abdominal pain. Inhalation exposure to high levels of petroleum "naphtha" may lead to inebriation, headache, and nausea. 
Page 6. HE/TA 81-292

v. DISCUSSION

Toluene and xylene cause profound drying of the skin, and the vapors are irritating to the mucous membranes. Both substances have marked central nervous system effects in concentrations ranging between 200 and $800 \mathrm{ppm}$ (parts per million), including headache, weakness, confusion, fatigue, nausea, exhilaration, dizziness, incoordination, drowsiness, and--at higher doses--coma. 1 Naphtha shares many of these central nervous system effects. Both toluene and xylene have been reported to be toxic to the liver, although acute toxic hepatitis (inflammation of the liver) has been described only with xylene exposure. Of three men painting in a closed chamber and exposed to $10,000 \mathrm{ppm}$ of xylene for 18 hours, one died and two recovered only after prolonged unconsciousness. The two survivors also developed reversible elevations in their liver enzymes. 3 Industrial painters chronically exposed to toluene were found to have enlarged livers, and $f$ ive in this group were also found to have a perforated nasal septum. 4 A teenage boy who intermittently sniffed toluene-containing glue for three years and was brought to the hospital after a 6 hour binge of glue sniffing developed both liver and kidney abnormalities. Although most of his kidney and liver tests returned to normal, the alkaline phosphatase remained elevated six months after the giue-sniffing episode. 5 A recent series on effects in persons who sniff toluene-containing inhalants noted gastrointestinal disturbances and nerve and muscle dysfunction in 25 people, but the authors made no mention of liver dysfunction. 6

Although no timely environmental monitoring was done in the Brodhead house, the evidence linking the illness with the exposure to the caulk is striking. Sustained and intense exposure to toluene and petroleum distillate vapors over a three day period, combined with low humidity in the house, may plausibly have induced the irritation and drying of the mucous membranes lining the nose that led to superficial erosions and bleeding in the most highly exposed individual. This is further supported by the timing of the nosebleed, the reports of nosebleeds in his wife and sons, the lack of a prior history of nosebleeds in any family member, and the absence of a demonstrable abnormality of blood clotting. Certainly the central nervous system effects described spontaneously by the affected individual--headache, weakness, and mild disorientation--are entirely compatible with short-term exposure to toluene above the level of $200 \mathrm{ppm}$ or continuous exposure to lower levels, and with exposure to other/solvents.

The relationship between the exposure to the caulk and abnormalities in liver function is less clear, since no liver function studies were performed until ten days after the man was first admitted to a hospital. However, the timing of the liver function abnormalities, their rapid decline (with the notable exception of the alkaline phosphatase), the absent history of any other exposure commonly associated with liver injury (such as alcohol abuse), the absence of history suggesting an infectious etiology, and the biological plausibility of toluene and/or xylene acting as hepatotoxins--especially in this unusual exposure setting--circumstantially implicate the caulk as a possible contributing cause of the man's transient liver function disturbance. If he had not developed a profound nosebleed, it is unlikely that his abnormal liver function would have been detected. 
Page 7. HE/TA 81-292

VI. RECOMMENDATIONS

1. Any caulking compound which is designed for use inside a house, or which may conceivably be used inside an occupied home or other closed space, should bear clear labelling information on the potential toxicity of its volatile elements and on the recommended safe handling and installation procedures.

2. A "butyl" or "rubber" caulk based on petroleum distillates and solvents should only be used with excellent ventilation. As with an oil-base paint containing potentially toxic volatiles, the caulk should not be used in a closed, occupied area without ventilation.

3. Professional installers of caulking compounds should be aware of the potential toxicity of the constituents of the caulk. Common sense suggests that they should recommend vacating the premises in any situation where large quantities of solvent-containing caulk are to be used in closed, unventilated living areas.

VII. AUTHORSHIP AND ACKNOWLEDGEMENTS

Investigation performed and report prepared by

Patricia Lynne Moody, M.D. Medical Officer, HETAB

Report typed by

Terry $0^{\prime}$ Neal

Clerk-Typist, HETAB

Technical assistance by the Division of Physical Sciences and Engineering is gratefully acknowledged. Thanks are also due to Michael Thun, M.D., and William Halperin, M.D. of the Industry Wide Studies Branch for their assistance on the site visit.

\section{REFERENCES}

1. Occupational Exposure to Toluene: Criteria for a Recommended Standard, the National Institute for Occupational Safety and Health, U.S. Department of Health, Education, and Welfare, 1973.

2. Occupational Exposure to Xylene: Criteria for a Recommended Standard, the National Institute for Ocupational Safety and Health, U.S. Department of Health, Education, and Welfare, 1975.

3. Morley, R. et al, "Xylene poisoning: a report on one fatal case and two cases of recovery after prolonged unconsciousness, "British Medical Journal, vol.3:442-443, 1970.

4. Greenburg, L. et al, "The effects of exposure to toluene in industry," JAMA, vol.118:573-78, 1942. 
Page 8. HE/TA 81-292

5. O'Brien, E.T. et a1, "Hepatorenal damage from toluene to a 'glue sniffer',"British Medical Journal, vol.2:29-30, 1971.

6. Streicher, Howard et al, "Syndromes of toluene sniffing in adults", Annals of Internal Medicine 94: 758-62, 1981.

IX. DISTRIBUTION AND AVAILABILITY

Copies of this Report are currently available upon request from NIOSH, "Division of Standards Development and Technology Transfer", Information Resources and Dissemination Section, 4676 Columbia Parkway, Cincinnati, Ohio 45226. After 90 days the report will be available through the National Technical Information availability through NTIS can be obtained from NIOSH, Publications Office at the Cincinnati, address.

Copies of this report have been sent to:

1. Homeowner, Brodhead, Kentucky

2. The Log Home Council

3. OSHA, Region IV

4. NIOSH, Region IV

5. Kentucky Department of Health 